\title{
Exposure to Ambient Air Pollution and Cognitive Impairment in Community-Dwelling Older Adults: The Korean Frailty and Aging Cohort Study
}

\author{
Jinyoung Shin ${ }^{1}{ }^{1}$, Seol-Heui Han ${ }^{2}$ and Jaekyung Choi ${ }^{1, *}$ \\ 1 Department of Family Medicine, Research Institute on Healthy aging, Konkuk University School of \\ Medicine, Konkuk University Medical Center, Seoul 05030, Korea; jyshin@kuh.ac.kr \\ 2 Department of Neurology, Research Institute on Healthy aging, Konkuk University School of Medicine, \\ Konkuk University Medical Center, Seoul 05030, Korea; alzdoc@kuh.ac.kr \\ * Correspondence: cjk@kuh.ac.kr; Tel.: +82-2-2030-7685; Fax: +82-2-2030-7749
}

Received: 28 August 2019; Accepted: 4 October 2019; Published: 7 October 2019

\begin{abstract}
The aim of this study was to investigate the associations between ambient air pollutants and cognitive impairment in Korean older adults. The cognitive function of 2,896 participants aged 70 to 84 years was measured using the Korean version of the mini-mental state examination, the digit span test, the word list learning test, and the frontal assessment battery. After matching the average concentrations of particulate matter $(\mathrm{PM})<10 \mu \mathrm{m}$ in size $\left(\mathrm{PM}_{10}\right)$ and $<2.5 \mu \mathrm{m}\left(\mathrm{PM}_{2.5}\right), \mathrm{NO}_{2}, \mathrm{CO}$, $\mathrm{SO}_{2}$, and $\mathrm{O}_{3}$ between 2013 and 2017, the association between air pollutants and cognitive scales was analyzed using a linear mixed regression and a multiple logistic regression analysis (after adjusting for age, sex, health related behaviors, socioeconomic status, comorbidity, and meteorological data). Exposure to $\mathrm{PM}_{2.5}, \mathrm{PM}_{10}, \mathrm{NO}_{2}, \mathrm{SO}_{2}$, and $\mathrm{CO}$ was associated with cognitive impairment above and beyond age or education level effects. Specifically, $\mathrm{PM}_{2.5}$ was negatively associated with most components of the cognitive scales (interquartile range for $\mathrm{PM}_{2.5}: 2.0 \mu \mathrm{g} / \mathrm{m}^{3}$, odds ratio for poor global cognition: $2.28,95 \%$ confidence interval: 1.60-3.26). These associations may be affected by sex, residence area, or alcohol intake. Conclusively, air pollutants, especially $\mathrm{PM}_{2.5}$, were associated with cognitive impairment, including global cognition, attention, memory, and executive function in Korean older adults aged $\geq 70$ years.
\end{abstract}

Keywords: air pollution; aged; particulate matter; memory; cognition

\section{Introduction}

Ambient air pollution, such as particulate matter $(\mathrm{PM})<10 \mu \mathrm{m}$ in size $\left(\mathrm{PM}_{10}\right)$ and $<2.5 \mu \mathrm{m}\left(\mathrm{PM}_{2.5}\right)$, nitrogen dioxide $\left(\mathrm{NO}_{2}\right)$, carbon monoxide $(\mathrm{CO})$, sulfur dioxide $\left(\mathrm{SO}_{2}\right)$, and ozone $\left(\mathrm{O}_{3}\right)$, has recently been recognized as one of the most serious health issues worldwide. A growing body of research has reported that air pollution is associated with impaired cognitive function and neuropathology reminiscent of neurodegenerative disorders, including dementia, Alzheimer's disease, and Parkinson's disease [1-3]. Cognitive impairment is a growing health problem for older adults. Up to $42 \%$ of older adults worldwide have been reported to have mild cognitive impairment [4]. Patients with mild cognitive impairment have been shown to be at risk of developing Alzheimer's disease and other neurodegenerative diseases [5,6]. The global number of individuals who live with dementia has increased rapidly, mainly due to the increase in the aging population and population growth, in general [7]. Multiple risk factors have been associated with the development and worsening of cognitive impairment, such as cardiovascular disease, reduced testosterone, insulin resistance, inflammation, health-related behaviors, and mental health status $[4,8,9]$. 
Although several risk factors for cognitive impairment are known, the causal links between ambient air pollution and cognitive impairment are not clear. In particular, previous studies have focused on the association between particulate matter or ozone and neurodegenerative disorders $[10,11]$. Due to the fact that PM occurs secondarily as a result of complex photochemical reactions with NOx or $\mathrm{SOx}$ [12], we have to consider the associations between $\mathrm{NO}_{2}, \mathrm{SO}_{2}$, and neurodegenerative disorders. Nevertheless, evidence for the associations between $\mathrm{CO}, \mathrm{SO}_{2}$, and $\mathrm{NO}_{2}$ and neurodegenerative disorders is lacking. Many previous studies on the relationship between air pollution and a decline in cognitive abilities investigated one main outcome, such as the incidence of dementia, Parkinson's disease, or hospitalization due to Alzheimer's disease, which had already progressed to neurodegenerative disease [13-15]. Furthermore, in previous studies, the assessment tool for cognitive function was often limited to working memory or the mini-mental state examination (MMSE) $[1,11,16]$. The aforementioned large study on the effect of air pollution in individuals with mild cognitive impairment identified Alzheimer's disease and dementia [2], but it was carried out in Western populations. Therefore, differences in race, lifestyle, air-pollutant concentration, and exposure duration may have affected the results. The level of air pollution in Korea has been shown to be higher than in the UK or the US (two countries in which the associations between cognitive impairment and air pollution have been shown) $[2,17,18]$. However, there has been little research on this association for the Korean older population.

This study aimed to investigate the association between ambient air pollutants and cognitive impairment, measured by a comprehensive assessment tool in Korean older adults, including the effect of health-related behavior and socioeconomic status.

\section{Materials and Methods}

\subsection{Study Participants}

The Korean Frailty and Aging Cohort study (KFACS) is an ongoing multicenter longitudinal study initiated in 2016. Sex- and age-stratified community residents aged 70 to 84 years were recruited at 10 centers in urban and rural regions throughout South Korea. From the total 3014 adults enrolled in 2016-2017, we analyzed 2896 subjects (96.1\%) after excluding the following residents: those that had moved within one-year $(n=99)$, those that had a diagnosis of dementia by a physician $(n=8)$, and those for whom we were missing residence information $(n=11)$. The protocol of the Korean Frailty and Aging Cohort study was approved by the Institutional Review Board (IRB) of the Clinical Research Ethics Committee of Konkuk University Medical Center, Seoul, Korea, and all participants provided written informed consent (IRB File Number: KUH1230027).

\subsection{Air Pollutant Variables}

We obtained the average concentrations of $\mathrm{PM}_{10}, \mathrm{NO}_{2}, \mathrm{CO}, \mathrm{SO}_{2}$, and $\mathrm{O}_{3}$, as measured hourly by the Korean Air Pollutants Emission Service in 2013-2017. Due to the fact that $\mathrm{PM}_{2.5}$ has only been measured in Korea since 2015, we applied the average concentrations of $\mathrm{PM}_{2.5}$ in the data from 2015 to 2017. The level of air pollutants measured at 268 nationwide surveillance stations located in residential areas was matched with the location of the participants' surveillance centers, and the average concentrations were calculated.

$\mathrm{PM}_{10}$ and $\mathrm{PM}_{2.5}$ were measured using $\beta$-ray attenuation (PM-711D, DONGIL GREENSYS, Seoul, Korea). $\mathrm{NO}_{2}$ was measured using chemiluminescence (CM2041, APM ENGINEERING CO., LTD, Gyeonggi-do, Korea). CO was measured using a nondispersive infrared sensor (ZKJ, DONGIL GREENSYS, Seoul, Korea). $\mathrm{SO}_{2}$ was measured with UV fluorescence (CM2050, APM ENGINEERING CO., LTD, Gyeonggi-do, Korea). $\mathrm{O}_{3}$ was measured using ultraviolet photometry (202, TOTAL ENGINEERING CO., LTD, Gyeonggi-do, Korea). All measurements of air pollutants were decided according to the Wireless Distributed Environmental Sensor Networks, which are stable to diverse environmental conditions [19]. The air pollutant measurements were made according to the standard 
operating procedure of the Korean Air Pollutants Emission Service of the National Institute of Environmental Research (Incheon, South Korea). The level of air pollutants and meteorological data, including temperature, rainfall, and wind speed are presented in Supplementary Table S1.

\subsection{Cognitive Impairment}

Cognitive impairment was assessed using the Korean version of the Consortium to Establish a Registry for Alzheimer's Disease Assessment Packet (CERAD-K) including the Korean version of the MMSE (MMSE-KC), the digit span test, the word list learning test $[20,21]$, and the frontal assessment battery (FAB) [22]. The MMSE is one of the most frequently used cognitive screening tools measuring orientation, memory, attention/concentration, language, and visuospatial function [23]. The Korean normative study of the MMSE was administered. Scores of 19 or less indicated severe cognitive impairment, scores of 20-23 indicated mild cognitive impairment, and scores of 24 or greater represented normal ability [24]. The original scale yielded a reliability of 0.92 [23]. The digit span test assessed concentration, attention, and immediate memory by asking participants to repeat a string of numbers in forward and backward order. The total score represented the longest series repeated without error [25]. The word list learning test (0-30 points) consisted of memory, recall, and word list recognition, in which the subjects were asked to memorize 10 visually presented words and the ability to learn new information was measured. In the word list recall test (0-10 points), the participants were asked to recall the words presented in the word list learning test after a delay, and their word recall ability was measured. In the word list recognition test (0-10 points), the participants were asked to distinguish the words presented in the word list learning test from new words, and their visual word recognition ability was measured [26]. FAB has become the most widely used screening tool for executive function. It takes a short time to complete and is easy to administer in clinical settings [27]. Executive function is defined as a variety of high-level cognitive abilities, such as planning, working memory, mental flexibility, and inhibition [28]. The FAB consisted of six subtests, which assessed conceptualization, mental flexibility, motor programming, sensitivity to interference, inhibitory control, and environmental autonomy. FAB scores were calculated from the summation of all subtests. The test has been used to identify Alzheimer's disease and other types of dementia, as well as psychiatric diseases and neurological problems, including movement disorders [28]. Higher values indicate better executive function (range $0-18$ ). All assessments were administered by trained researchers and the data obtained were audited by a research modulator.

\subsection{Other Variables}

Questionnaires concerning socioeconomic status, the Korean version of activities of daily living instrument (K-ADL), the Korean version of instrumental activities of daily living (K-IADL), medical histories, and health-related behaviors were surveyed by trained researchers. We categorized smoking status as being either current (for residents who were smoking daily or intermittently at the time of the survey), or never/former (for residents who smoked in the past but were not currently smoking). To account for alcohol consumption, we categorized participants as either "never", "less than once per week", or "more than once per week". Physical inactivity was defined as the lowest $20 \%$ of the sex-specific total energy consumed (kcal/week), which was assigned by the intensity of physical activity following metabolic equivalents (MET $=\mathrm{kcal} \mathrm{kg}^{-1} \mathrm{~h}^{-1}$ ) using the International Physical Activity Questionnaire. Participants with less than $494.65 \mathrm{kcal} /$ week for men, or less than $283.50 \mathrm{kcal} /$ week for women, were defined as being physically inactive [29].

We also obtained the following demographic information: years of education $(<9, \geq 9)$, marital status (married/with partner and divorced/widowed/unmarried), household income $(<1,000,000 \mathrm{won} / \mathrm{month}$ or $\geq 1,000,000 \mathrm{won} / \mathrm{month})$, length at current residence ( 1 to 5 years/ $>5$ years), and place of residence (rural or urban). Body mass index (BMI) was calculated as body weight divided by height squared $\left(\mathrm{kg} / \mathrm{m}^{2}\right)$. Carlson's comorbidity index was used to indicate overall health status, and was calculated using 18 conditions, excluding dementia [30]. 


\subsection{Statistical Analyses}

Comparison of continuous variables (i.e., demographics, socioeconomic characteristics, and health-related behaviors of the study population) are presented as means with standard errors. Categorical variables are presented as numbers and percentages. As the level of air pollutants and cognitive scores were not normally distributed according to the Shapiro-Wilk test, we evaluated the relationship between the average annual concentrations of air pollutants and the cognitive scales using Spearman's correlation analysis (Supplementary Table S2). We used log-transformed cognitive scales in the following analysis because of the non-normal distribution. The $\beta$ coefficients ( $95 \%$ confidence intervals $(\mathrm{CI})$ ) for the log-transformed cognitive scales per one standard deviation (SD) increase in air pollutants were analyzed by a linear mixed model. In all analyses, each center was adjusted as a random effect. Age, sex, body mass index, smoking, alcohol intake, physical activity, education, household income, marital status, Carlson's comorbidity index, length of time at the same residence, meteorological data, residence area, $\mathrm{PM}_{2.5}, \mathrm{PM}_{10}, \mathrm{CO}, \mathrm{SO}_{2}, \mathrm{NO}_{2}$, and $\mathrm{O}_{3}$ were adjusted as fixed effects [25]. We evaluated the odds ratios for the lowest quartile of log-transformed cognitive scales according to the per interquartile increase in $\mathrm{PM}_{2.5}, \mathrm{PM}_{10}, \mathrm{NO}_{2}, \mathrm{SO}_{2}, \mathrm{CO}$, and $\mathrm{O}_{3}$ using multiple logistic regression analysis (after adjusting for confounding factors). We conducted stratified analyses to investigate possible effect modifications by demographics, socioeconomic characteristics, and health-related behaviors in subgroup analysis. Two-tailed $P<0.05$ was considered significant. All statistical analyses were conducted using IBM SPSS for Windows, version 24.0 (IBM Corp., Armonk, NY, USA).

\section{Results}

\subsection{Demographic Characteristics of the Study Population}

The demographics, socioeconomic characteristics, and health-related behaviors of the study population are summarized in Table 1 . The mean age was 76 years (range 70-84) and women represented $52.5 \%$ of the participants. Among the total participants, $77.8 \%$ had lived more than five years in their current residence and about $70 \%$ resided in urban areas. (Table 1).

Table 1. Characteristics of this study populations $(n=2896)$.

\begin{tabular}{cc}
\hline Variables & Mean \pm SD or N (\%) \\
\hline Age, (min/max), years & $76.0 \pm 3.9(70.0 / 84.0)$ \\
Sex & $1377(47.5)$ \\
Female & $1519(52.5)$ \\
Smoking & \\
Current & $1104(38.1)$ \\
Never/former & $1792(61.9)$ \\
Alcohol intake & \\
Never/Less than one time per week & $520(18.0)$ \\
More than one time per week & $2376(82.0)$ \\
Physical activity, kcal/week & \\
Active & $2580(89.1)$ \\
Inactive & $316(10.9)$ \\
Education, years & \\
$<9$ & $1396(48.2)$ \\
$\geq 9$ & $1500(51.8)$ \\
Marital status & $1950(67.3)$ \\
Married/with partner & $946(32.7)$ \\
Divorced/widowed/unmarried & $1370(47.3)$ \\
Household income, won/monthly & $1526(52.7)$ \\
$<1,000,000$ & \\
$\geq 1,000,000$ &
\end{tabular}


Table 1. Cont.

\begin{tabular}{cc}
\hline Variables & Mean \pm SD or N (\%) \\
\hline Length of current residence, year & \\
$1 \sim 5$ & $643(22.2)$ \\
$>5$ & $2253(77.8)$ \\
Residence & \\
Urban & $2013(69.9)$ \\
Rural & $883(30.1)$ \\
Body mass index, kg/m ${ }^{2}$ & $24.5 \pm 3.1$ \\
K-ADL (min/max) & $7.1 \pm 0.4(7 / 14)$ \\
K-IADL (min/max) & $0.3 \pm 0.8(0 / 9)$ \\
MMSE-KC (range: $8-30)$ & $0.48 \pm 0.79$ \\
Digit span-forward (range: 0-9) & $25.6 \pm 3.3$ \\
Digit span-backward (range: 0-8) & $5.8 \pm 1.5$ \\
Word list memory (range: 0-29) & $3.3 \pm 1.1$ \\
Word list recall (range: 0-10) & $16.7 \pm 4.3$ \\
Recall storage (\%) & $5.5 \pm 2.1$ \\
Carlson comorbidity index (range: & $77.4 \pm 24.2$ \\
Word list recognition, (range: 0-10) & $8.6 \pm 1.9$ \\
Frontal assessment battery test (range: 0-18) & $13.4 \pm 3.0$ \\
\hline
\end{tabular}

K-ADL: Korean version of activities of daily living instrument, K-IADL: Korean version of instrumental activities of daily living instrument, MMSE-KC: Korean version of the mini-mental state examination. Physical inactivity was defined as the lowest $20 \%$ of the gender-specific total energy consumed (kcal/week); $<494.65 \mathrm{kcal}$ for men or $<283.50 \mathrm{kcal}$ for women.

\subsection{Cognitive Scales according to the Increases in Air Pollutants}

\subsubsection{Linear Mixed Model}

The variations in cognitive scales per increase of one standard deviation in the air pollutants, after adjusting for all covariates, including meteorological data, are presented in Table 2. $\mathrm{PM}_{2.5}$ was negatively associated with all cognitive scales. The magnitude of the coefficients for $\mathrm{PM}_{2.5}$ was larger than the decrease in cognitive function for each increase of one year in age. $\mathrm{PM}_{10}$ was negatively associated with the MMSE-KC scores and the digit span-forward scores. $\mathrm{PM}_{10}$ showed null or positive associations with memory scales. $\mathrm{CO}, \mathrm{SO}_{2}$, and $\mathrm{NO}_{2}$ showed negative associations with memory scales, however, there were inconsistent findings between $\mathrm{CO}, \mathrm{SO}_{2}, \mathrm{NO}_{2}, \mathrm{O}_{3}$, and cognitive scales.

\subsubsection{Multiple logistic model}

Odds ratios for the lowest quartile of log-transformed cognitive scales according to the per interquartile increase of air pollutants are presented in Figure 1. An increase in $\mathrm{PM}_{2.5}$ quartile level was associated with an increased probability of the low cognitive scales, including global cognition, attention, memory, and executive function (all $\mathrm{P}<0.05$ ). $\mathrm{PM}_{10}, \mathrm{NO}_{2}$, and $\mathrm{O}_{3}$ were associated with higher risks for poor global cognition and executive function. $\mathrm{CO}$ was associated with a higher risk for poor global cognition, low attention, and executive function. $\mathrm{SO}_{2}$ was associated with a higher risk for poor global cognition and memory function. Except for $\mathrm{PM}_{2.5}$, these associations tended to be inconsistent. 
Table 2. Results of regression models ${ }^{1}$ for cognitive scales according to the increases of air pollutants and participants' characteristics.

\begin{tabular}{|c|c|c|c|c|c|c|c|c|c|}
\hline & 1-SD & MMSE-KC & $\begin{array}{l}\text { Digit Forward } \\
\text { Span }\end{array}$ & $\begin{array}{c}\text { Digit Backward } \\
\text { Span }\end{array}$ & $\begin{array}{l}\text { Word List } \\
\text { Memory }\end{array}$ & Word List Recall & Recall Storage & $\begin{array}{c}\text { Word List } \\
\text { Recognition }\end{array}$ & FAB_Score \\
\hline $\mathrm{PM}_{2.5}$ & $1.5 \mu \mathrm{g} / \mathrm{m}^{3}$ & $\begin{array}{c}-0.010 \\
(-0.019,-0.001)^{2}\end{array}$ & $\begin{array}{c}-0.022 \\
(-0.040,-0.005)^{2}\end{array}$ & $\begin{array}{c}-0.039 \\
(-0.057,-0.020)^{2}\end{array}$ & $\begin{array}{c}-0.024 \\
(-0.036,-0.011)^{2}\end{array}$ & $\begin{array}{c}-0.036 \\
(-0.054,-0.018)^{2}\end{array}$ & $\begin{array}{c}-0.024 \\
(-0.038,-0.010)^{2}\end{array}$ & $\begin{array}{c}-0.016 \\
(-0.029,-0.003)^{2}\end{array}$ & $\begin{array}{c}-0.037 \\
(-0.048,-0.025)^{2}\end{array}$ \\
\hline $\mathrm{PM}_{10}$ & $4.6 \mu \mathrm{g} / \mathrm{m}^{3}$ & $\begin{array}{c}-0.035 \\
(-0.050,-0.020)^{2}\end{array}$ & $\begin{array}{c}-0.029 \\
(-0.057,-0.001)^{2}\end{array}$ & $\begin{array}{c}0.022 \\
(-0.008,0.053)\end{array}$ & $\begin{array}{c}0.049 \\
(0.015,0.083)^{2}\end{array}$ & $\begin{array}{c}-0.011 \\
(-0.033,0.011)\end{array}$ & $\begin{array}{c}-0.014 \\
(-0.031,0.003)\end{array}$ & $\begin{array}{c}0.001 \\
(-0.015,0.016)\end{array}$ & $\begin{array}{c}-0.002 \\
(-0.021,0.017)\end{array}$ \\
\hline $\mathrm{CO}$ & $0.08 \mathrm{ppm}$ & $\begin{array}{c}0.044 \\
(0.032,0.056)^{2}\end{array}$ & $\begin{array}{c}0.052 \\
(0.029,0.075)^{2}\end{array}$ & $\begin{array}{c}-0.022 \\
(00.046,0.003)\end{array}$ & $\begin{array}{c}-0.035 \\
(-0.063,-0.007)^{2}\end{array}$ & $\begin{array}{c}-0.018 \\
(-0.034,-0.003)^{2}\end{array}$ & $\begin{array}{c}-0.005 \\
(-0.017,0.007)\end{array}$ & $\begin{array}{c}-0.007 \\
(-0.018,0.004)\end{array}$ & $\begin{array}{c}-0.006 \\
(-0.019,0.007)\end{array}$ \\
\hline $\mathrm{SO}_{2}$ & $0.9 \mathrm{ppb}$ & $\begin{array}{c}0.007 \\
(-0.005,0.020)\end{array}$ & $\begin{array}{c}0.058 \\
(0.035,0.082)^{2}\end{array}$ & $\begin{array}{c}-0.032 \\
(-0.058,-0.007)^{2}\end{array}$ & $\begin{array}{c}-0.010 \\
(-0.039,0.019)\end{array}$ & $\begin{array}{c}-0.038 \\
(-0.060,-0.017)^{2}\end{array}$ & $\begin{array}{c}-0.022 \\
(-0.039,-0.006)^{2}\end{array}$ & $\begin{array}{c}-0.011 \\
(-0.026,0.004)\end{array}$ & $\begin{array}{c}0.007 \\
(-0.005,0.020)\end{array}$ \\
\hline $\mathrm{NO}_{2}$ & $7.7 \mathrm{ppb}$ & $\begin{array}{c}0.012 \\
(0.001,0.025)^{2}\end{array}$ & $\begin{array}{c}-0.026 \\
(-0.050,-0.003)^{2}\end{array}$ & $\begin{array}{c}0.015 \\
(-0.009,0.040)\end{array}$ & $\begin{array}{c}0.034 \\
(0.006,0.063)^{2}\end{array}$ & $\begin{array}{c}-0.019 \\
(-0.035,-0.003)^{2}\end{array}$ & $\begin{array}{c}-0.007 \\
(-0.042,0.015)\end{array}$ & $\begin{array}{c}-0.003 \\
(-0.015,0.008)\end{array}$ & $\begin{array}{c}-0.019 \\
(-0.034,-0.005)^{2}\end{array}$ \\
\hline $\mathrm{O}_{3}$ & $4.3 \mathrm{ppb}$ & $\begin{array}{c}0.045 \\
(0.027,0.062)^{2}\end{array}$ & $\begin{array}{c}0.062 \\
(0.029,0.094)^{2}\end{array}$ & $\begin{array}{c}-0.029 \\
(-0.064,0.006)\end{array}$ & $\begin{array}{c}0.009 \\
(-0.031,0.048)\end{array}$ & $\begin{array}{c}0.034 \\
(0.018,0.049)^{2}\end{array}$ & $\begin{array}{c}0.013 \\
(0.001,0.025)^{2}\end{array}$ & $\begin{array}{c}0.010 \\
(-0.001,0.021)\end{array}$ & $\begin{array}{c}0.011 \\
(0.002,0.019)^{2}\end{array}$ \\
\hline Age & 1 year & $\begin{array}{c}-0.006 \\
(-0.008,-0.005)^{2}\end{array}$ & $\begin{array}{c}-0.009 \\
(-0.012,-0.006)^{2}\end{array}$ & $\begin{array}{c}-0.009 \\
(-0.012,-0.006)^{2}\end{array}$ & $\begin{array}{c}-0.020 \\
(-0.024,-0.017)^{2}\end{array}$ & $\begin{array}{c}-0.026 \\
(-0.030,-0.022)^{2}\end{array}$ & $\begin{array}{c}-0.012 \\
(-0.016,-0.009)^{2}\end{array}$ & $\begin{array}{c}-0.010 \\
(-0.013,-0.007)^{2}\end{array}$ & $\begin{array}{c}-0.009 \\
(-0.011,-0.007)^{2}\end{array}$ \\
\hline Education & 1 year & $\begin{array}{c}-0.011 \\
(-0.010,-0.012)^{2}\end{array}$ & $\begin{array}{c}-0.018 \\
(-0.016,-0.020)^{2}\end{array}$ & $\begin{array}{c}-0.024 \\
(-0.021,-0.026)^{2}\end{array}$ & $\begin{array}{c}-0.016 \\
(-0.014,-0.019)^{2}\end{array}$ & $\begin{array}{c}-0.017 \\
(-0.013,-0.021)^{2}\end{array}$ & $\begin{array}{c}-0.005 \\
(-0.002,-0.008)^{2}\end{array}$ & $\begin{array}{c}-0.006 \\
(-0.003,-0.009)^{2}\end{array}$ & $\begin{array}{c}-0.023 \\
(-0.021,-0.025)^{2}\end{array}$ \\
\hline
\end{tabular}

${ }^{1} \beta$ coefficients ( $95 \%$ confidence intervals) of log-transformed cognitive scales per one standard deviation increase of air pollutants or one year of age (increase) and education (decrease) were assessed by linear mixed model. Age, sex, body mass index, smoking, alcohol intake, physical activity, education, household income, marital status, Carlson's comorbidity index, length of same residence, meteorological data, residence area, $\mathrm{PM}_{2.5}, \mathrm{PM}_{10}, \mathrm{CO}, \mathrm{SO}_{2}, \mathrm{NO}_{2}, \mathrm{O}_{3}$ (selected air pollutant was not included in the model) were adjusted as fixed effects, and each center was adjusted as random effects. Although there were highly correlated among the air pollutants, we confirmed the unchanged overall results when excluding combinations of these variables (data were not shown). $2 \mathrm{P}<0.05$, SD: standard deviation, $\mathrm{PM}_{2.5}$ : particulate matter $<2.5 \mu \mathrm{m}$ in diameter, $\mathrm{PM}_{10}$ : particulate matter $<10 \mu \mathrm{m}$ in diameter, $\mathrm{NO}_{2}$ : nitrogen dioxide, $\mathrm{SO}_{2}$ : sulfur dioxide, $\mathrm{CO}$ : carbon monoxide, $\mathrm{O}_{3}$ : ozone. MMSE-KC: Korean version of the mini-mental state examination; FAB: frontal assessment battery test score. 

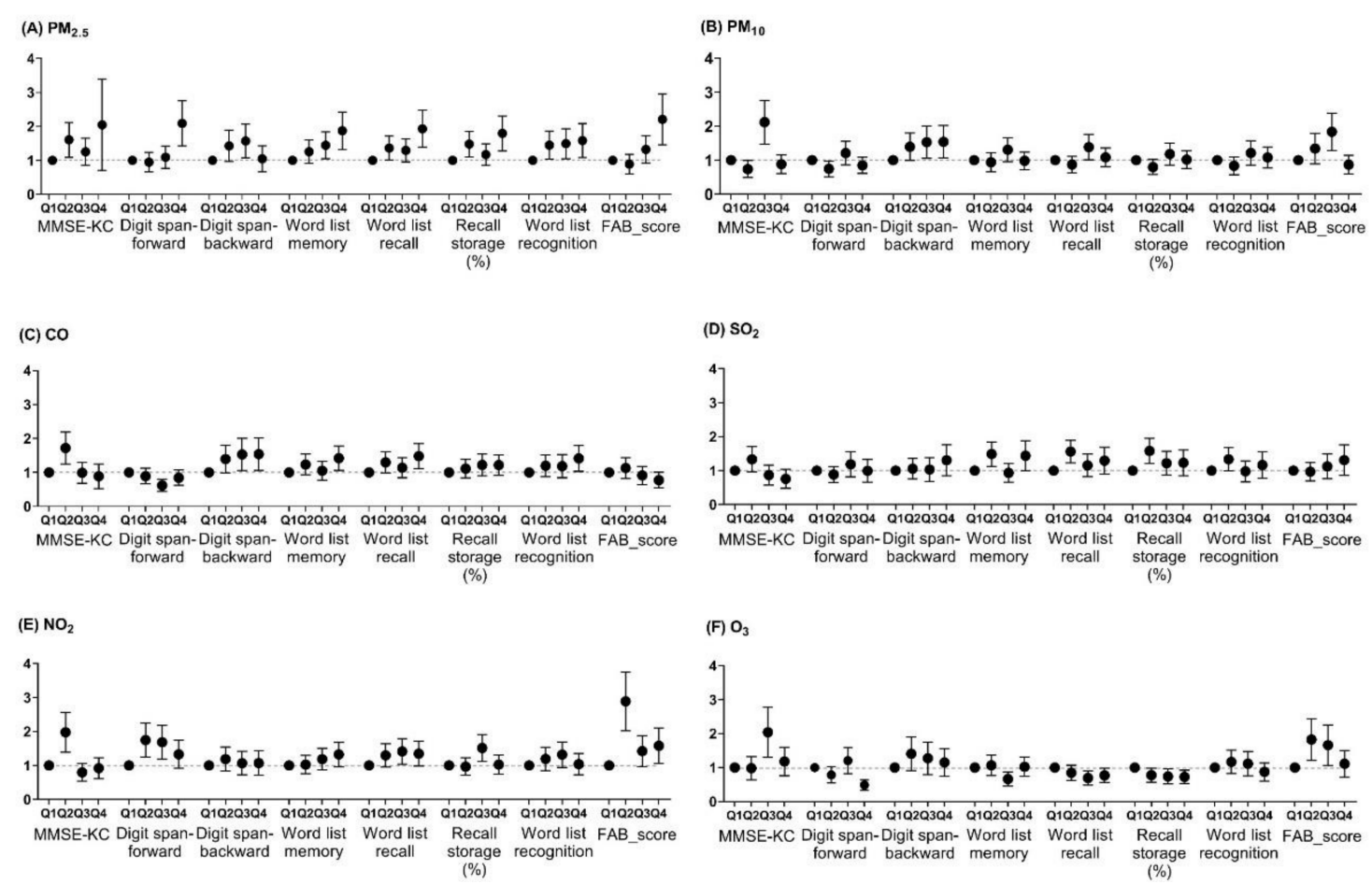

Figure 1. Odds ratios and 95\% confidence intervals for the lowest quartile of log-transformed cognitive scales according to quartiles of air pollutants.

\subsection{Cognitive Impairment Due to the Increase of $P M_{2.5}$ and Participants' Characteristics}

We found negative associations between $\mathrm{PM}_{2.5}$ and the following attributes: increased age, female sex, less than nine years of education, rural residence, low income, current smoking, alcohol intake more than once per week, and physical inactivity (Figure 2). However, it varied according to the cognitive scales. In the subgroup analysis, we confirmed the effect modification for sex, residence area, or alcohol intake ( $P$-value $>0.05)$. In female participants, recall storage scores showed a negative association with $\mathrm{PM}_{2.5}$, while in male participants, they did not. Being male showed a negative association between the recognition test and $\mathrm{PM}_{2.5}$. However, females had a null association with this test. Rural residents showed negative associations with $\mathrm{PM}_{2.5}$ and digit span test and FAB score, while participants living in urban areas had null associations. Alcohol intake of more than once per week was associated with cognitive impairment related to $\mathrm{PM}_{2.5}$. Alcohol intake of less than once per week was associated with lower scores in the recognition test. Participants with education level more than nine years showed the null associations with increase of $\mathrm{PM}_{2.5}$. 


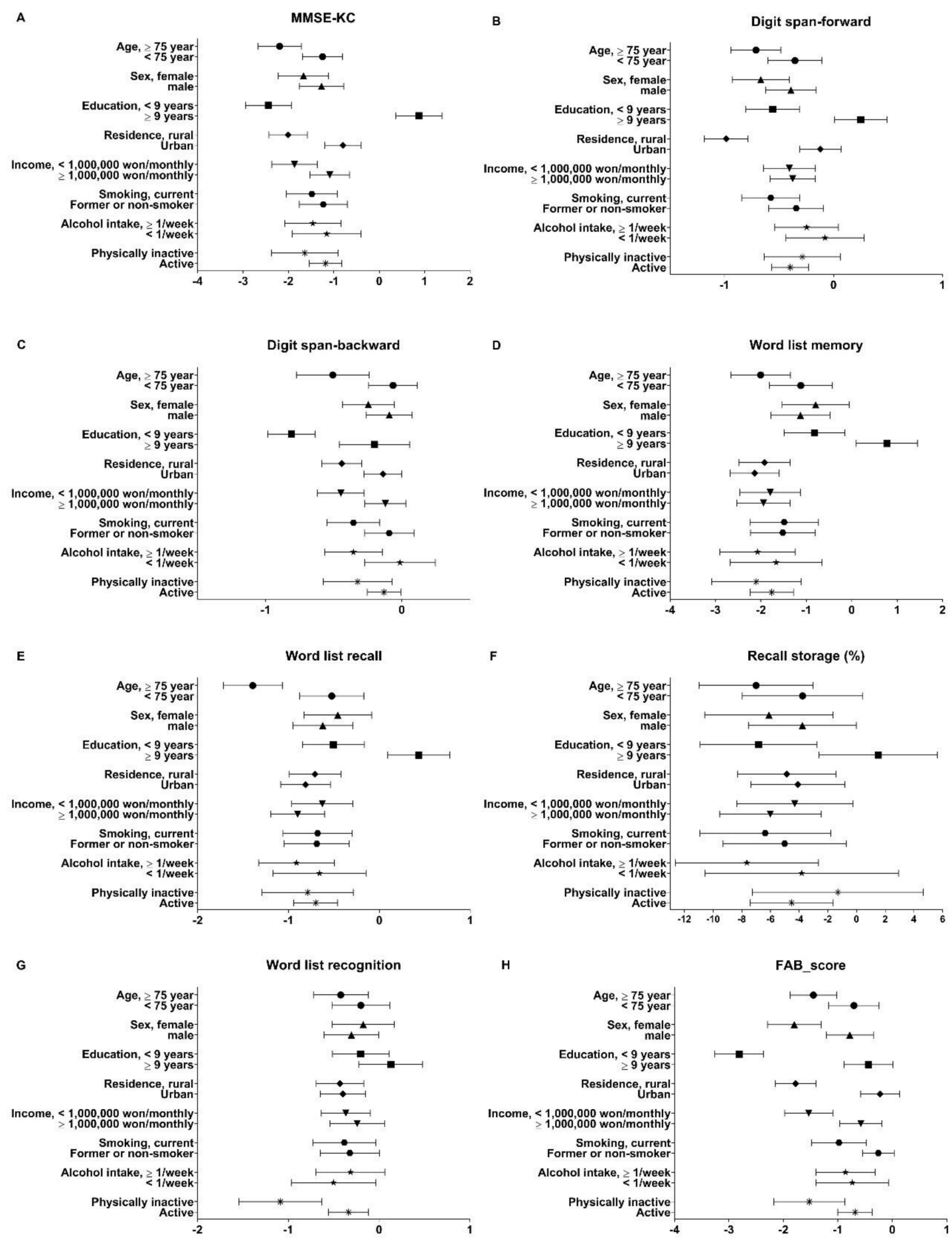

Figure 2. The $\beta$ coefficients of cognitive scales according to the increase of particulate matter (PM) $<2.5 \mu \mathrm{m}\left(\mathrm{PM}_{2.5}\right)$ according to participants' characteristics.

\section{Discussion}

In the present cross-sectional study on Korean older adults, we evaluated the associations between air pollutants and cognitive function, including global cognition, attention, memory, and executive function. We found that exposure to $\mathrm{PM}_{2.5}, \mathrm{PM}_{10}, \mathrm{NO}_{2}, \mathrm{SO}_{2}$, and $\mathrm{CO}$ was associated with cognitive impairment. We found a strong association between higher $\mathrm{PM}_{2.5}$ exposure and worse performance in most of the cognitive scales. The effect of air pollutants on the cognitive scales was significant, compared to that of age and education level. Specifically, global cognition, attention, and recall memory were vulnerable to exposure to air pollutants. Most of the existing evidence for a link between air pollution 
and cognitive impairment comes from studies of patients diagnosed with dementia $[7,10,13,14]$, or of populations younger than our study's participants (mean age: 56.3 years vs. 76.0 years) [11]. This study adds to existing research on air pollution and cognition in older adults by demonstrating links between various pollutants, such as $\mathrm{NO}_{2}, \mathrm{SO}_{2}$, and $\mathrm{CO}$, and the scores on various cognitive scales for older Korean adults (age $\geq 70$ ), considering all possible confounding factors.

However, we did not find a linear association between air pollutants and cognitive function, as in a previous study [16]. We believe that the reason for this finding is a threshold effect at low levels of air pollutants [31]. Below a cut-off value for the air pollutants, the effect may be not clear. Therefore, we may find out the difference associations in Table 2 and Figure 1 . We also found several effect modifications for sex, residence area, and alcohol intake. Females were vulnerable in terms of recall storage and males were vulnerable in terms of recognition. The prevalence of Alzheimer's disease and other dementias have a higher prevalence in females than in males [7]. However, the association between air pollution and cognitive impairment should be considered not only with respect to the longer lifespan of females [7], but also the higher exposure from transport use [32] or proven risks in men [31]. Therefore, a mixed pattern may be represented with respect to sex. On the other hand, participants residing in rural areas showed worse cognitive function in our study. A possible cause could be the indoor pollution in rural areas, although we did not measure the level of indoor pollution [33]. The air purifier market has tripled from 2016 to 2018 in Korea [34]. The use of air purifiers is expected to have an impact on the association between air pollution and cognition in the future.

In this study, among the air pollutants, $\mathrm{PM}_{2.5}$ was confirmed as an obvious risk factor for cognitive impairment, supporting several previous studies [35]. The adverse neurological mechanism of air pollutants may be related to neuro-inflammation associated with oxidative stress and cytokine production [36,37]. Exposure to high ambient $\mathrm{PM}_{2.5}$ accelerated cognitive decline and all-cause dementia up to $21 \%$ in US community-dwelling older adults aged 65 to 79 years [38]. Systemic exposure to $\mathrm{PM}_{2.5}$ potentially contributes to the inflammatory, glial, and amyloid pathology responses via bloodstream uptake, and to direct infiltration of the central nervous system $[1,38]$. However, in our study, the associations between $\mathrm{PM}_{10}, \mathrm{NO}_{2}, \mathrm{SO}_{2}, \mathrm{CO}, \mathrm{O}_{3}$, and the cognitive scales were not evident. There are three possible reasons for this. First, the effect of $\mathrm{PM}_{2.5}$ on cognitive impairment may be remarkable compared to other pollutants. The contributions of soil dust and natural sources of $\mathrm{PM}_{2.5}$ were smaller than they were for $\mathrm{PM}_{10}$ in Korea [39], while a high contribution of $\mathrm{PM}_{2.5}$, which comes from secondary aerosol sources via the atmospheric chemical reaction of gaseous pollutants, such as $\mathrm{SO}_{2}$ and $\mathrm{NO}_{2}$ that originate from fuel combustion, could be more hazardous to human health [39]. Second, very small and soluble $\mathrm{PM}_{2.5}$ can cross the blood-brain barrier, accessing the central nervous system and contributing to the development of neurotoxicity, unlike $\mathrm{PM}_{10}$ [3]. It has been suggested that the reduced systemic effects of $\mathrm{PM}_{10}$ result from the inability of coarse fraction PM to infiltrate the bloodstream or directly assess the brain. Third, an area-based approach, which assigns exposures at the level of each participant's community, county, postcode, or census tract, may be more adequate for evaluating the effects of $\mathrm{PM}_{2.5}$, which is dispersed relatively homogenously across space, than for $\mathrm{PM}_{10}, \mathrm{NO}_{2}, \mathrm{SO}_{2}, \mathrm{CO}$, and $\mathrm{O}_{3}$ [35]. This potential measurement error, or exposure estimation error, may provide a possible explanation for the heterogeneity observed in previous studies on cognitive impairment for different pollutants, statistical models, geographic regions, and time periods [33,35]. In Mexican older adults aged $\geq 60$ years with five-year exposures at a mean $\mathrm{PM}_{2.5}$ concentration of $12.9 \mu \mathrm{g} / \mathrm{m}^{3}$ (min-max $\left.2.4-27.8 \mu \mathrm{g} / \mathrm{m}^{3}\right), \mathrm{PM}_{2.5}$ was negatively associated with cognitive function, as in our study (mean: $25.5 \mu \mathrm{g} / \mathrm{m}^{3}$, min-max $23.4-28.5 \mu \mathrm{g} / \mathrm{m}^{3}$ ) [33], although the study examined longer exposure durations and lower levels than our study.

We did not find any link between $\mathrm{O}_{3}$ and cognitive impairment in our study. Moreover, the positive associations between $\mathrm{O}_{3}$ and MMSE-KC scores, digit-forward span scores, word list recall, recall storage, and FAB scores were unexpected results, compared to a previous limited study [10]. However, a positive association between $\mathrm{O}_{3}$ and the logical memory of adults aged 60 and older was found in a study by Gatto et al. in California, USA (2000-2006) [40]. Interestingly, a positive association was seen 
at the range of 34-49 $\mathrm{ppb}$ in $\mathrm{O}_{3}$, which was similar to the level in our study (21.6-36.5 ppb), while the null association was seen at a higher level in that study ( $>49 \mathrm{ppb}$ in $\mathrm{O}_{3}$ ) [40]. In a Taiwanese study by Jung et al., 10-year exposure to $\mathrm{O}_{3}$ in people aged $\geq 65$ years increased the risk of Alzheimer's disease, according to the International Classification of Diseases, ninth revision [10]. The level of $\mathrm{O}_{3}$ in the study by Jung et al. was higher than in our study (mean $88.97 \pm 7.80 \mathrm{ppb}$ and range 52.79-106.74 ppb in Jung et al. vs. mean $26.3 \pm 4.3 \mathrm{ppb}$ and range 21.6-36.5 in our study). Although we can suggest that the discrepancies were due to different levels of $\mathrm{O}_{3}$ at different latitudes or exposure of the participants, further research is needed to explore the association between $\mathrm{O}_{3}$ and cognitive function.

This study had several limitations. First, it was not possible to establish causality because this was a cross-sectional study based on a recruitment survey from a cohort study. Second, we matched the community of residence and local air pollutant levels using the enrollment center location. Therefore, measurement errors for the air pollutants are possible. Third, undiagnosed dementia patients with low MMSE-KC scores may have been included in this study, although we initially excluded patients diagnosed by a physician with dementia. Fourth, due to the lack of information about the exposure window related to the development of an individual's cognitive impairment, we could only estimate the air pollutant exposure duration from the data in previous studies $[1,2,16]$. Excluding participants $(n=99)$ who moved within one year considering the minimum exposure or the difference in exposure duration for $\mathrm{PM}_{2.5}$ (2015-2017) and non- $\mathrm{PM}_{2.5}$ (2013-2017) may have biased study findings. Finally, genetic predisposition (such as having the APOE-4 gene, which may increase the risk of Alzheimer's disease), and traffic-related exposure were not considered in our models. However, we made an effort to minimize enrollment selection bias by matching age and sex for the older adults, and by obtaining missing values by visiting participants' homes or by surveying via telephone. We also performed our analysis after adjustment for several confounding variables.

\section{Conclusions}

Air pollutants, especially $\mathrm{PM}_{2.5}$, were associated with cognitive impairment, including global cognition, attention, memory, and executive function in Korean older adults aged $\geq 70$ years. These associations differed according to sex, residence area, and health-related behavior, such as alcohol intake. This information may be helpful for policy-making to control air pollution as a risk factor for cognitive impairment.

Supplementary Materials: Supplementary materials are available online at http://www.mdpi.com/1660-4601/16/19/ 3767/s1. Table S1: Distribution of annual concentrations of air pollutants and meteorological data in 2013-2017, Table S2: Correlations between cognitive scales and the annual concentrations of air pollutants, 2013-2017 (PM 2.5 : 2015-2017).

Author Contributions: Conceptualization, J.S., S.-H.H., and J.C.; methodology, J.S.; formal analysis, J.S. and S.-H.H.; writing—original draft preparation, J.S. and J.C.; writing—review and editing, S.-H.H.; and funding acquisition, J.S.

Funding: This research was funded by Konkuk University Medical Center Research Grant 2019.

Acknowledgments: We thank to the study participants and the staff of the Korean Frailty and Aging Cohort Study for their cooperation.

Conflicts of Interest: The authors declare no conflict of interest. The funders had no role in the design of the study; in the collection, analyses, or interpretation of data; in the writing of the manuscript; or in the decision to publish the results.

\section{References}

1. Kilian, J.; Kitazawa, M. The emerging risk of exposure to air pollution on cognitive decline and Alzheimer's disease-Evidence from epidemiological and animal studies. Biomed. J. 2018, 41, 141-162. [CrossRef] [PubMed]

2. Cullen, B.; Newby, D.; Lee, D.; Lyall, D.M.; Nevado-Holgado, A.J.; Evans, J.J.; Pell, J.P.; Lovestone, S.; Cavanagh, J. Cross-sectional and longitudinal analyses of outdoor air pollution exposure and cognitive function in UK Biobank. Sci. Rep. 2018, 8, 12089. [CrossRef] [PubMed] 
3. Fu, P.; Guo, X.; Cheung, F.M.H.; Yung, K.K.L. The association between PM2.5 exposure and neurological disorders: A systematic review and meta-analysis. Sci. Total. Environ. 2019, 655, 1240-1248. [CrossRef] [PubMed]

4. Hu, C.; Yu, D.; Sun, X.; Zhang, M.; Wang, L.; Qin, H. The prevalence and progression of mild cognitive impairment among clinic and community populations: A systematic review and meta-analysis. Int. Psychogeriatr. 2017, 29, 1595-1608. [CrossRef] [PubMed]

5. Small, B.J.; Fratiglioni, L.; Viitanen, M.; Winblad, B.; Backman, L. The course of cognitive impairment in preclinical Alzheimer disease: Three- and 6-year follow-up of a population-based sample. Arch. Neurol. 2000, 57, 839-844. [CrossRef] [PubMed]

6. Flicker, C.; Ferris, S.H.; Reisberg, B. Mild cognitive impairment in the elderly: Predictors of dementia. Neurology 1991, 41, 1006-1009. [CrossRef] [PubMed]

7. Nichols, E.; Szoeke, C.E.I.; Vollset, S.E.; Abbasi, N.; Abd-Allah, F.; Abdela, J.; Aichour, M.T.E.; Akinyemi, R.O.; Alahdab, F.; Asgedom, S.W.; et al. Global, regional, and national burden of Alzheimer's disease and other dementias, 1990-2016: A systematic analysis for the Global Burden of Disease Study 2016. Lancet Neurol. 2019, 18, 88-106. [CrossRef]

8. Fougere, B.; Delrieu, J.; Del Campo, N.; Soriano, G.; Sourdet, S.; Vellas, B. Cognitive Frailty: Mechanisms, Tools to Measure, Prevention and Controversy. Clin. Geriatr. Med. 2017, 33, 339-355. [CrossRef]

9. Panza, F.; Lozupone, M.; Solfrizzi, V.; Sardone, R.; Dibello, V.; Di Lena, L.; D’Urso, F.; Stallone, R.; Petruzzi, M.; Giannelli, G.; et al. Different Cognitive Frailty Models and Health- and Cognitive-related Outcomes in Older Age: From Epidemiology to Prevention. J. Alzheimers. Dis. 2018, 62, 993-1012. [CrossRef]

10. Jung, C.R.; Lin, Y.T.; Hwang, B.F. Ozone, particulate matter, and newly diagnosed Alzheimer's disease: A population-based cohort study in Taiwan. J. Alzheimers. Dis. 2015, 44, 573-584. [CrossRef]

11. Wurth, R.; Kioumourtzoglou, M.A.; Tucker, K.L.; Griffith, J.; Manjourides, J.; Suh, H. Fine Particle Sources and Cognitive Function in an Older Puerto Rican Cohort in Greater Boston. Environ. Epidemiol. 2018, 2. [CrossRef] [PubMed]

12. Fiotakis, K.; Vlachogianni, T. Airborne Particulate Matter and Human Health: Toxicological Assessment and Importance of Size and Composition of Particles for Oxidative Damage and Carcinogenic Mechanisms AU VALAVANIDIS, ATHANASIOS. J. Environ. Sci. Health C 2008, 26, 339-362. [CrossRef]

13. Chen, H.; Kwong, J.C.; Copes, R.; Tu, K.; Villeneuve, P.J.; van Donkelaar, A.; Hystad, P.; Martin, R.V.; Murray, B.J.; Jessiman, B.; et al. Living near major roads and the incidence of dementia, Parkinson's disease, and multiple sclerosis: A population-based cohort study. Lancet 2017, 389, 718-726. [CrossRef]

14. Chen, H.; Kwong, J.C.; Copes, R.; Hystad, P.; van Donkelaar, A.; Tu, K.; Brook, J.R.; Goldberg, M.S.; Martin, R.V.; Murray, B.J.; et al. Exposure to ambient air pollution and the incidence of dementia: A population-based cohort study. Environ. Int. 2017, 108, 271-277. [CrossRef] [PubMed]

15. Culqui, D.R.; Linares, C.; Ortiz, C.; Carmona, R.; Diaz, J. Association between environmental factors and emergency hospital admissions due to Alzheimer's disease in Madrid. Sci. Total. Environ. 2017, 592, 451-457. [CrossRef] [PubMed]

16. Ailshire, J.A.; Crimmins, E.M. Fine particulate matter air pollution and cognitive function among older US adults. Am. J. Epidemiol. 2014, 180, 359-366. [CrossRef]

17. Yoo, S.E.; Park, J.S.; Lee, S.H.; Park, C.H.; Lee, C.W.; Lee, S.B.; Yu, S.D.; Kim, S.Y.; Kim, H. Comparison of Short-Term Associations between PM2.5 Components and Mortality across Six Major Cities in South Korea. Int. J. Environ. Res. Public Health 2019, 16, 2872. [CrossRef] [PubMed]

18. American Lung Association. State of the Air 2016. Available online: http://www.lung.org/assets/documents/ healthy-air/stateof-the-air/sota-201 (accessed on 10 September 2019).

19. Broday, D.M.; The Citi-Sense Project Collaborators. Wireless Distributed Environmental Sensor Networks for Air Pollution Measurement-The Promise and the Current Reality. Sensors 2017, 17, 2263. [CrossRef]

20. Lee, J.H.; Lee, K.U.; Lee, D.Y.; Kim, K.W.; Jhoo, J.H.; Kim, J.H.; Lee, K.H.; Kim, S.Y.; Han, S.H.; Woo, J.I. Development of the Korean version of the Consortium to Establish a Registry for Alzheimer's Disease Assessment Packet (CERAD-K): Clinical and neuropsychological assessment batteries. J. Gerontol. B-Psychol. 2002, 57, P47-P53. [CrossRef] 
21. Lee, D.Y.; Lee, K.U.; Lee, J.H.; Kim, K.W.; Jhoo, J.H.; Kim, S.Y.; Yoon, J.C.; Woo, S.I.; Ha, J.; Woo, J.I. A normative study of the CERAD neuropsychological assessment battery in the Korean elderly. J. Int. Neuropsychol. Soc. 2004, 10, 72-81. [CrossRef]

22. Kim, T.H.; Huh, Y.; Choe, J.Y.; Jeong, J.W.; Park, J.H.; Lee, S.B.; Lee, J.J.; Jhoo, J.H.; Lee, D.Y.; Woo, J.I.; et al. Korean version of frontal assessment battery: Psychometric properties and normative data. Dement. Geriatr. Cogn. Disord. 2010, 29, 363-370. [CrossRef] [PubMed]

23. Folstein, M.F.; Folstein, S.E.; McHugh, P.R. "Mini-mental state”: A practical method for grading the cognitive state of patients for the clinician. J. Psychiatr. Res. 1975, 12, 189-198. [CrossRef]

24. Lee, D.Y.; Lee, K.U.; Lee, J.H.; Kim, K.W.; Jhoo, J.H.; Youn, J.C.; Kim, S.Y.; Woo, S.I.; Woo, J.I. A normative study of the mini-mental state examination in the Korean elderly. J. Korean Neuropsychiatr. Assoc. 2002, 41, 508-525.

25. Wu, F.; Guo, Y.; Zheng, Y.; Ma, W.; Kowal, P.; Chatterji, S.; Wang, L. Social-Economic Status and Cognitive Performance among Chinese Aged 50 Years and Older. PLoS ONE 2016, 11, e0166986. [CrossRef] [PubMed]

26. Chung, S.C.; Choi, M.H.; Kim, H.S.; Lee, J.C.; Park, S.J.; Jeong, U.H.; Baek, J.H.; Gim, S.Y.; Choi, Y.C.; Lee, B.Y.; et al. Differences in and correlations between cognitive abilities and brain volumes in healthy control, mild cognitive impairment, and Alzheimer disease groups. Clin. Anat. 2016, 29, 473-480. [CrossRef] [PubMed]

27. Hurtado-Pomares, M.; Carmen Terol-Cantero, M.; Sanchez-Perez, A.; Peral-Gomez, P.; Valera-Gran, D.; Navarrete-Munoz, E.M. The frontal assessment battery in clinical practice: A systematic review. Int. J. Geriatr. Psychiatry 2018, 33, 237-251. [CrossRef]

28. Moreira, H.S.; Costa, A.S.; Castro, S.L.; Lima, C.F.; Vicente, S.G. Assessing Executive Dysfunction in Neurodegenerative Disorders: A Critical Review of Brief Neuropsychological Tools. Front. Aging Neurosci. 2017, 9, 369. [CrossRef]

29. Son, J.H.; Kim, S.Y.; Won, C.W.; Choi, H.R.; Kim, B.S.; Park, M.S. Physical frailty predicts medical expenses in community-dwelling, elderly patients: Three-year prospective findings from living profiles of older people surveys in Korea. Eur. Geriatr. Med. 2015, 6, 412-416. [CrossRef]

30. D'Hoore, W.; Sicotte, C.; Tilquin, C. Risk adjustment in outcome assessment: The Charlson comorbidity index. Methods Inf. Med. 1993, 32, 382-387.

31. Shin, J.; Park, J.Y.; Choi, J. Long-term exposure to ambient air pollutants and mental health status: A nationwide population-based cross-sectional study. PLoS ONE 2018, 13, e0195607. [CrossRef]

32. James, S.L.; Abate, D.; Abate, K.H.; Abay, S.M.; Abbafati, C.; Abbasi, N.; Abbastabar, H.; Abd-Allah, F.; Abdela, J.; Abdelalim, A.; et al. Global, regional, and national incidence, prevalence, and years lived with disability for 354 diseases and injuries for 195 countries and territories, 1990-2017: A systematic analysis for the Global Burden of Disease Study 2017. Lancet 2018, 392, 1789-1858. [CrossRef]

33. Salinas-Rodriguez, A.; Fernandez-Nino, J.A.; Manrique-Espinoza, B.; Moreno-Banda, G.L.; Sosa-Ortiz, A.L.; Qian, Z.M.; Lin, H. Exposure to ambient PM2.5 concentrations and cognitive function among older Mexican adults. Environ. Int. 2018, 117, 1-9. [CrossRef] [PubMed]

34. Air Purifier Sales Shoot Up as Fine Dust Worries Shoppers. Available online: http://koreajoongangdaily.joins. com/news/article/article.aspx?aid=3059575 (accessed on 10 September 2019).

35. Power, M.C.; Adar, S.D.; Yanosky, J.D.; Weuve, J. Exposure to air pollution as a potential contributor to cognitive function, cognitive decline, brain imaging, and dementia: A systematic review of epidemiologic research. Neurotoxicology 2016, 56, 235-253. [CrossRef] [PubMed]

36. Calderón-Garcidueñas, L.; Reed, W.; Maronpot, R.R.; Henriquez-Roldán, C.; Delgado-Chavez, R.; Calderón-Garcidueñas, A.; Dragustinovis, I.; Franco-Lira, M.; Aragón-Flores, M.; Solt, A.C.; et al. Brain Inflammation and Alzheimer's-Like Pathology in Individuals Exposed to Severe Air Pollution. Toxicol. Pathol. 2004, 32, 650-658. [CrossRef] [PubMed]

37. Heppner, F.L.; Ransohoff, R.M.; Becher, B. Immune attack: The role of inflammation in Alzheimer disease. Nat. Rev. Neurosci. 2015, 16, 358. [CrossRef]

38. Cacciottolo, M.; Wang, X.; Driscoll, I.; Woodward, N.; Saffari, A.; Reyes, J.; Serre, M.L.; Vizuete, W.; Sioutas, C.; Morgan, T.E.; et al. Particulate air pollutants, APOE alleles and their contributions to cognitive impairment in older women and to amyloidogenesis in experimental models. Transl. Psychiatry 2017, 7, e1022. [CrossRef] [PubMed] 
39. Ryou, H.g.; Heo, J.; Kim, S.-Y. Source apportionment of PM10 and PM2.5 air pollution, and possible impacts of study characteristics in South Korea. Environ. Pollut. 2018, 240, 963-972. [CrossRef]

40. Gatto, N.M.; Henderson, V.W.; Hodis, H.N.; St John, J.A.; Lurmann, F.; Chen, J.-C.; Mack, W.J. Components of air pollution and cognitive function in middle-aged and older adults in Los Angeles. Neurotoxicology 2014, 40, 1-7. [CrossRef] article distributed under the terms and conditions of the Creative Commons Attribution (CC BY) license (http://creativecommons.org/licenses/by/4.0/). 